\title{
Comparison Between Microstructures of Conventional and New Raney Catalysts
}

\author{
B. H. Zeifert", H. A. Calderón ${ }^{* *}$, J. Salmones B. ${ }^{* * *}$, J. G. Cabañas-Moreno $^{* *}$ \\ *Instituto Politécnico Nacional, ESIQIE, Av. IPN s/n, Edif. 7, UPALM, 07738, D.F., México \\ **Instituto Politécnico Nacional, ESFM, Apdo. Postal 75-373, 07300 México, D.F., México \\ **** Instituto Mexicano del Petróleo, Eje Central Lázaro Cárdenas 152, 07730 México, D.F., México
}

Raney-type catalysts are widely applied in a variety of commercial processes in the chemical industries. Conventionally, Raney nickel catalysts are produced by leaching aluminum from cast Al$\mathrm{Ni}$ alloys; they consist of porous nickel particles having small amounts $(3-5 \mathrm{wt}$. \%) of residual aluminum and surface areas in the range of $50-130 \mathrm{~m}^{2} / \mathrm{g}$ [1]. In recent years, reports have been made regarding the production of Raney catalysts by leaching of precursor alloys obtained by mechanical alloying (MA) [2-4]. In these studies, the microstructural characterization has been quite limited in detail. The results of our own work with Raney nickel and nickel-iron catalysts have clearly shown that, compared to conventional Raney catalysts, those derived from precursor alloys prepared by MA possess important advantages regarding simplicity and reproducibility of production, as well as catalytic performance. In order to better understand these findings, we have now conducted a comparative microstructural characterization of conventional and MA Raney catalysts.

Catalyst preparation has been reported elsewhere $[3,4]$. Materials characterized in the present study included the as-milled MA alloys before and after leaching. For comparison, it was included a commercial Raney nickel catalyst. All materials were characterized by XRD, SEM, TEM and EDS.

Before leaching, the MA powders consisted mainly of nodular particles with sizes mostly in the range $0.5-2 \mu \mathrm{m}$ (Fig. 1a). The individual particles contained crystallites with sizes mainly in the $5-$ $10 \mathrm{~nm}$ range (not shown). SAD patterns obtained from individual particles gave clear evidence for the existence of the NiAl intermetallic phase, in agreement with the results of XRD.

Particle shape and size did not noticeably change under the SEM after leaching (Fig. 1b). In comparison, the commercial Raney nickel catalyst consisted of powders of a much larger and heterogeneous size as well as irregular in shape (Fig. 1c). However, TEM observations indicated more interesting differences in the catalysts particles; a highly porous structure was observed in the powders derived from MA alloys (Fig. 2a). This structure consists of a mixture of nanocrystallites and intertwined filaments or tubules, the latter having diameters of about 5-20 nm, The size of the crystallites was similar to that found in the MA powders (Fig. 2b). In turn, in the commercial Ni catalyst only bigger crystallites could be observed (not shown). More detailed studies of the MAderived Raney catalysts are presently under way, including HREM, to gain a better understanding of their structural features [5].

[1] S. Sane et al., Appl. Catalysis 9 (1984), 69.

[2] E. Ivanov et al., Solid State Ionics 60 (1993), 299.

[3] B. Zeifert et al., Catalysis Letters, 63 (1999), 161.

[4] B.H. Zeifert et al., Materials Letters, 43 (2000), 244.

[5] This research was supported by IPN and CONACYT (project 28617-U). BHZ, HAC and JGCM acknowledge the support from COFAA-IPN fellowships. 

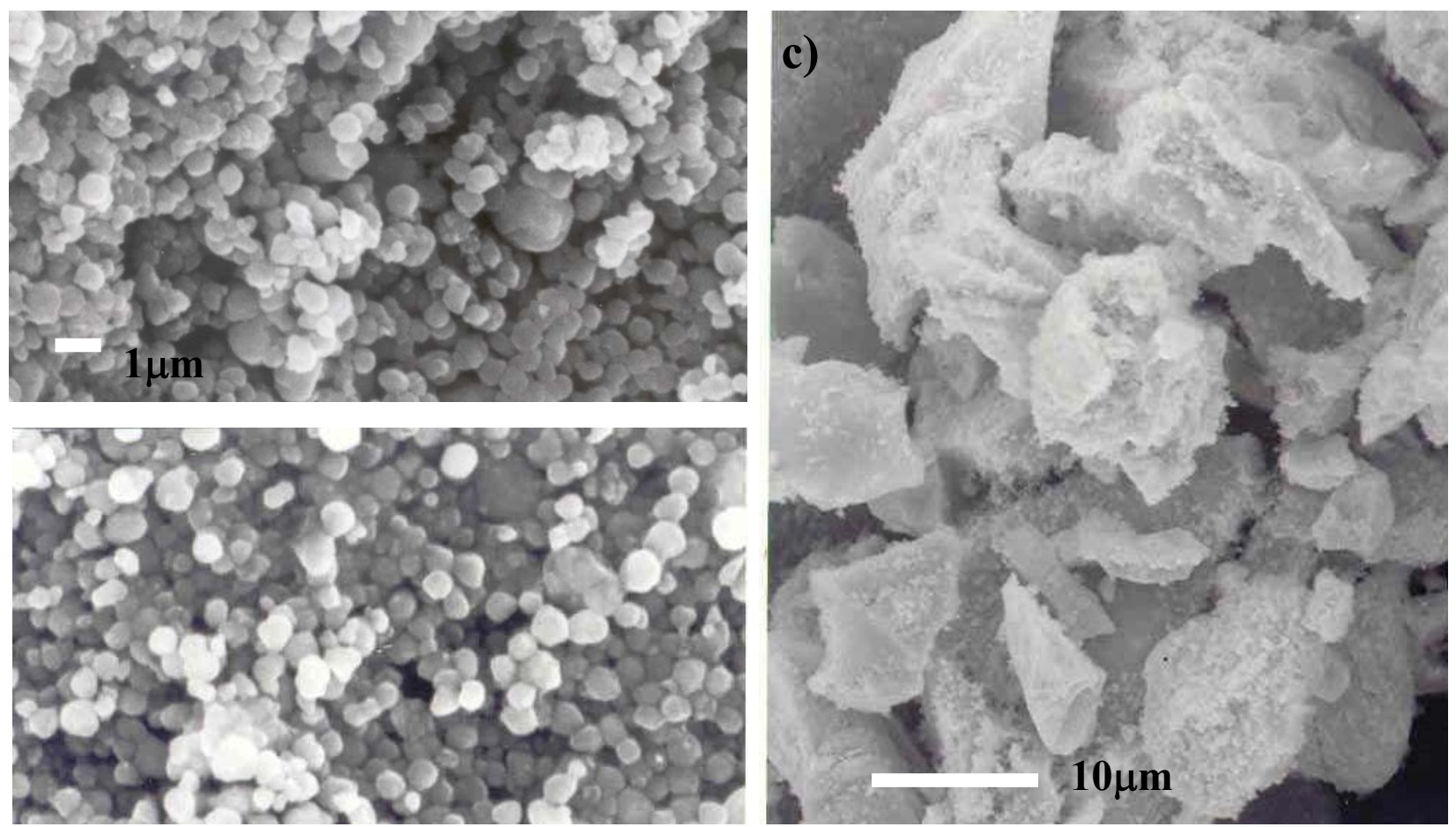

FIG. 1. MA powders (a) before and (b) after leaching, and (c) conventional Raney nickel catalyst.

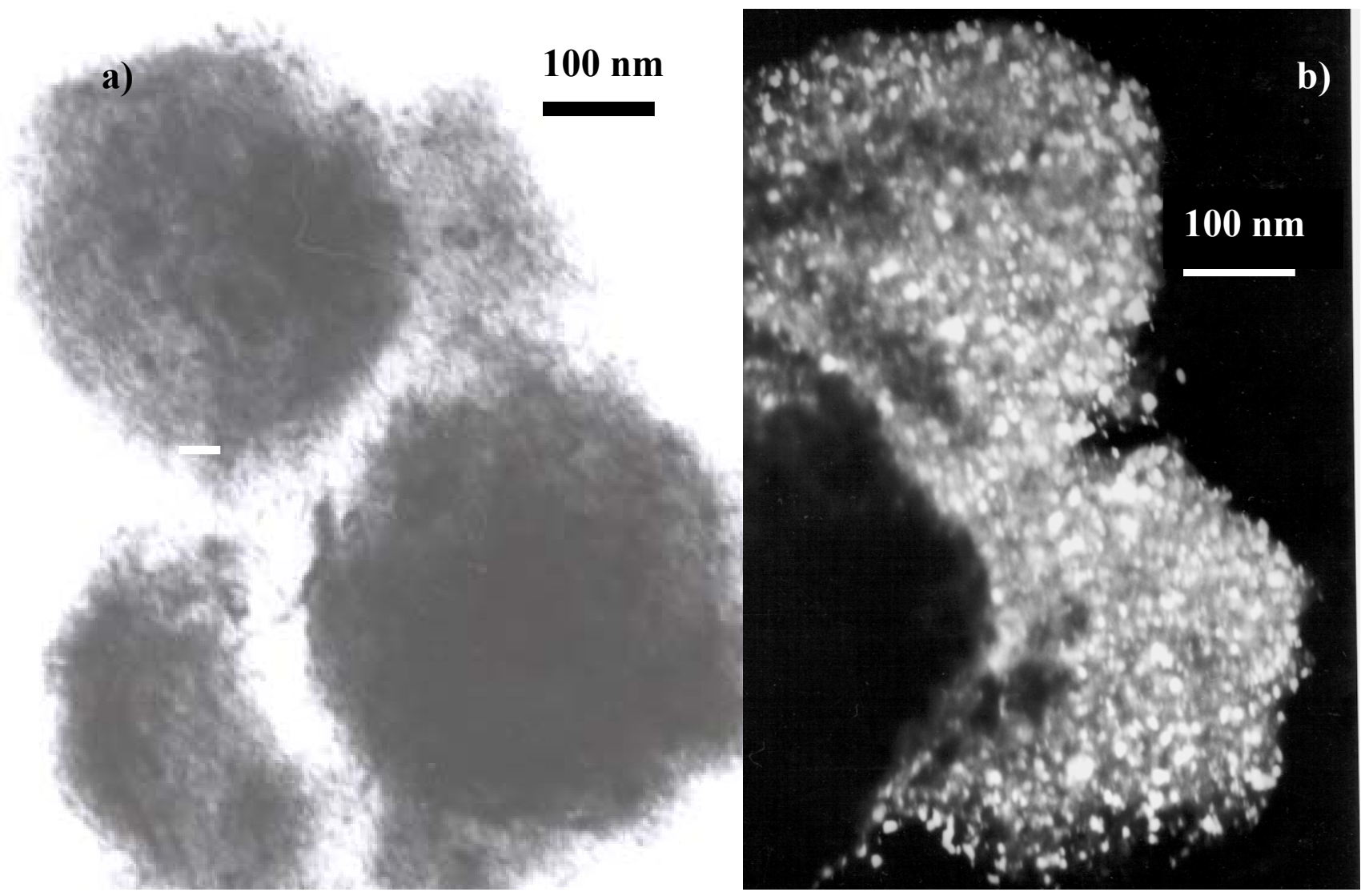

FIG. 2. MA Raney catalysts: a) highly porous particles and b) size of the crystallites. 